\title{
Effect of Residual Stresses of GTA Welding for Dissimilar Materials
}

\author{
Harinadh Vemanaboina ${ }^{a} \oplus^{\circledR}$, Gundabattini Edison ${ }^{a}$, Suresh Akella ${ }^{b}$ \\ ${ }^{a}$ School of Mechanical Engineering - SMEC, VIT University, Vellore, Tamilnadu, India \\ ${ }^{b}$ Sreyas Institute of Engineering \& Technology, Hyderabad, India
}

Received: December 02, 2017; Revised: March 18, 2018; Accepted: May 16, 2018

\begin{abstract}
The purpose of the present work is to understand the evolution of residual stresses in weldments. The study made to weld the multipass dissimilar of Nickel-based superalloy Inconel 625 and stainless steel 316L using Continuous Current Gas Tungsten Arc Welding (CCGTAW) and Pulsed Current Gas Tungsten Arc Welding (PCGTAW) process employing ERNiCrMo-3 and ERNiCr-3 fillers. The $\mathrm{L}_{4}$ orthogonal array was used in the present experimentation process. Analysis of Variance (ANOVA) is applied for the optimization and to identify the critical parameters. In welding process, the size of the lattice size will be stressed due to welding parameters; the lattice dimension is measured by non-destructive technique X-Ray diffraction to investigate residual stress in the weldment in the lateral surface of the plate. X-Ray Radiography test has evaluated the quality of welds. The results show that root gap is a critical parameter and filler wire and weld processes are not critical.
\end{abstract}

Keywords: GTAW, Dissimilar Materials, Multipass Welding, Residual Stress, XRD, ANOVA.

\section{Introduction}

Welding of similar or dissimilar materials having individual thermal properties (density, linear expansion, specific heat, conductivity) and mechanical properties (yield strength, Poisson's ratio) lead to changes in residual stress and distortion and metallurgical properties. This causes inhomogeneous plastic deformation leading to defects like distortion and residual stresses in the welded parts. Stresses within a material are thoroughly isolated into two essential orders (a) within and (b) external surfaces. External stress is related to exterior loads coupled during the manufacturing or machining and cyclic operations process of material; internal stress is naturally present inside the material even though no external forces are acting on it.

Dissimilar materials joining will minimize the weight and cost of the component, where demand for such materials are necessary for various industrial application such as nuclear, automobile, aerospace, power plants and chemical plants. The multi-pass welding process is used for welding of thick metals. For each of the passes (heat), equal intervals of time are taken to fill the material at groove designed. The material undergoes transient heating and cooling cycles during these processes. The size of the lattice size of metal is stressed even after the metal cools down to room temperature. The researchers had developed multi-purpose 3D models for the welding process to study the temperatures, distortions, and residual stresses. Simulation of butt joints for weldments using the single pass, multi-pass welding with element birth and death techniques for laser beam and arc welding process using ANSYS packages ${ }^{1,2,3,4}$. The initial, temperature dependent material properties, convection, and radiation boundary conditions are also adopted for welding processes. Heat is concentrated at the welding zone during the welding process; the weld portion will undergo thermal cycles for thick workpieces while filling of material in grooves, during the addition of the material non-uniform heating and cooling occurs during each pass for thick materials, this leads to the generation of residual stresses in the weld structures. Murugan ${ }^{5}$ has studied the multipass welding of various thick plates, the temperature and residual stresses measured either side of the weldment pass by pass, with thermocouples and X-Ray diffraction. Residual stress developed during the machining or manufacturing process, these were measured using the X-ray diffraction ${ }^{6}$ is a nondestructive measurement method using this equipment we can know the atomic lattice spacing in the measured component. Lei $\mathrm{XU}^{7}$ had discussed weld with K-PAW process for making T-joint with thin plate used for aerospace application and study about the measurement of residual stress using synchrotron X-ray diffraction and FEA. The residual stress is measured using ultrasonic techniques; welding was carried out with TIG and A-TIG processes for thick plate welds ${ }^{8}$. The residual stress measurement is done through XRD, before and after post weld treatment for butt tube joints ${ }^{9}$. Laser beam welding process has narrow fusion zone and narrower residual stress distribution in weld structures, the butt joints are made for thick plates pre and post weldment vibratory stress relief (VSR) treatment for weldment at low frequency, where this technique was used for reducing the residual stress to $100 \mathrm{MPa}^{10}$. Surface residual stresses were measured by ED-Hole 
drilling strain gauge method, and it was also evaluated in thickness using X-ray diffraction, the study also includes the metallurgical characterization ${ }^{11}$. The detailed study of dissimilar butt welding joints are made for Inconel 625 and AISI 316L, with both continuous and pulsed current GTAW process, and two filler wires were included for weldability, metallurgical and mechanical properties of joints ${ }^{12}$. The investigation of residual stress of dissimilar butt pipe welding was studied by the nondestructive capability of LCR ultrasonic method, the finite element model, hole-drilling and ultrasonic stress measurements methods are employed on two dissimilar welded pipes ${ }^{13}$.

It is evident from the literature; no studies were reported on residual stress measurement for multipass dissimilar weldments of SS316L to Inconel 625. In the present work, the multipass dissimilar joints are achieved with both continuous current GTAW and pulsed current GTAW processes by using the ERNiCr-3 and ERNiCrMo-3 filler wires. The $\mathrm{L}_{4}$ orthogonal array is employed to identify the critical parameters for generation of residual stresses. The residual stress is measured in the transverse direction to weld. The measurement is carried out at fusion zone in the weldment by using the X-Ray diffraction non-destructive technique.

\section{Experimental Work}

The chemical composition of the base metals Inconel 625 to SS316L and filler metals ERNiCrMo-3 and ERNiCr-3 is shown in Table 1. ERNiCrMo-3 and ERNiCr-3 fillers are utilized to weld dissimilar metal combinations, for example, steel, stainless steel, Inconel, and Inconel alloys for GTAW, GMAW, and ASAW processes. The dimensions of the samples employed for the present study of $110 \mathrm{~mm}$ x $60 \mathrm{~mm}$ x $5 \mathrm{~mm}$. The standard single V-groove design was employed for butt joints, with an included angle of $60^{\circ}$ is used for dissimilar joints. The investigation is involved in both CCGTA welding and PCGTA welding processes. The $\mathrm{L}_{4}$ orthogonal array was chosen for the present experimentation as shown in Table 2. The processes parameters employed in multi-pass GTAW process (CCGTAW and PCGTAW) of dissimilar welding (Inconel 625 to SS316L) are represented in Table 3.

In this study, three passes are employed for each weld sample for adding of different filler materials at root, filler and cap pass at groove designed for formation of the joint. The current was used for CCGTAW process were 140 Amps and for PCGTAW was 160 Amps with background current was 80 Amps, welding voltage $13-15$ Volts and flow rate 10

Table 1. Chemical properties of the materials

\begin{tabular}{|c|c|c|c|c|c|c|c|c|c|}
\hline & \multicolumn{9}{|c|}{ Element ( $\%$ by mass) } \\
\hline & $\mathrm{Ni}$ & $\mathrm{C}$ & $\mathrm{Mn}$ & S & $\mathrm{Cu}$ & $\mathrm{Si}$ & $\mathrm{Cr}$ & $\mathrm{P}$ & Others \\
\hline Inconel 625 & Min 58 & $\begin{array}{c}\operatorname{Max} \\
0.1\end{array}$ & $\begin{array}{c}\operatorname{Max} \\
0.5\end{array}$ & $\begin{array}{c}\operatorname{Max} \\
0.015\end{array}$ & Max 0.5 & $\begin{array}{c}\operatorname{Max} \\
0.5\end{array}$ & $20-23$ & $\begin{array}{c}\operatorname{Max} \\
0.015\end{array}$ & $\begin{array}{c}\text { Fe Max 5, Al 0.40, Mo } \\
8-10, \text { Ti max } 0.1\end{array}$ \\
\hline SS316L & App 12.00-18.00 & $\begin{array}{l}\text { Max } \\
0.03\end{array}$ & $\begin{array}{l}\text { Max } \\
2.00\end{array}$ & $\begin{array}{c}\text { Max } \\
0.030\end{array}$ & - & $\begin{array}{l}\operatorname{Max} \\
1.00\end{array}$ & $16.00-18.00$ & $\begin{array}{c}\operatorname{Max} \\
0.045\end{array}$ & Mo 2-3, \\
\hline ErNiCrMo-3 & Min 64 & $\begin{array}{c}\operatorname{Max} \\
0.1\end{array}$ & $\begin{array}{c}\operatorname{Max} \\
0.5\end{array}$ & $\begin{array}{c}\operatorname{Max} \\
0.015\end{array}$ & Max 0.50 & $\begin{array}{l}\operatorname{Max} \\
0.50\end{array}$ & $22.0-23.0$ & $\begin{array}{c}\operatorname{Max} \\
0.015\end{array}$ & $\begin{array}{c}\text { Fe Max } 1.0, \mathrm{Al} \text { Max } 0.40 \\
\mathrm{Nb} 3.6-4.5, \mathrm{Mo} 0.015, \mathrm{Ti} \\
\max 0.40\end{array}$ \\
\hline ERNiCr-3 & Min 67 & $\begin{array}{l}\text { Max } \\
0.05\end{array}$ & $\begin{array}{l}2.5- \\
3.5\end{array}$ & $\begin{array}{c}\operatorname{Max} \\
0.015\end{array}$ & $\operatorname{Max} 0.50$ & $\begin{array}{l}\operatorname{Max} \\
0.50\end{array}$ & $18.0-22.0$ & $\begin{array}{c}\operatorname{Max} \\
0.015\end{array}$ & $\begin{array}{c}\mathrm{Fe} \operatorname{Max} 3.0, \mathrm{Nb} 2.0-3.0, \mathrm{Ti} \\
\max 0.75\end{array}$ \\
\hline
\end{tabular}

Table 2. $\mathrm{L}_{4}$ Orthogonal array

\begin{tabular}{clll}
\hline Trails & 1 & 2 & 3 \\
\hline 1 & 1 & 1 & 1 \\
2 & 1 & 2 & 2 \\
3 & 2 & 1 & 2 \\
4 & 2 & 2 & 1 \\
\hline
\end{tabular}

Table 3. Process parameters and its levels

\begin{tabular}{|c|c|c|c|c|c|c|c|c|c|c|}
\hline \multirow{2}{*}{ S.No } & \multirow{2}{*}{ Process } & \multirow{2}{*}{ Root gap } & \multirow{2}{*}{ Filler } & \multirow{2}{*}{$\begin{array}{l}\text { Pulsed } \\
\text { Current }\end{array}$} & \multicolumn{3}{|c|}{ Base current or welding current } & \multirow{2}{*}{ Voltage } & \multirow{2}{*}{$\begin{array}{c}\text { Avg } \\
\text { Welding } \\
\text { speed }\end{array}$} & \multirow{2}{*}{$\begin{array}{l}\text { Heat } \\
\text { input }\end{array}$} \\
\hline & & & & & P1 & P2 & P3 & & & \\
\hline & & $\mathrm{mm}$ & & Amps & & Amps & & Volts & $\mathrm{mm} / \mathrm{sec}$ & $\mathrm{kJ} / \mathrm{mm}$ \\
\hline 1 & $\mathrm{CC}$ & 1.8 & ERNiCr-3 & - & 140 & 140 & 140 & 13 & 95.9 & 0.86 \\
\hline 2 & $\mathrm{CC}$ & 2.0 & ERNiCrMo-3 & - & 140 & 140 & 140 & 13 & 152.39 & 1.25 \\
\hline 3 & $\mathrm{PC}$ & 1.8 & ERNiCrMo-3 & 80 & 160 & 160 & 160 & 15 & 60.92 & 0.74 \\
\hline 4 & $\mathrm{PC}$ & 2.0 & ERNiCr-3 & 80 & 160 & 160 & 160 & 15 & 85.58 & 1.16 \\
\hline
\end{tabular}


$\mathrm{L} /$ min was maintained constant for both the processes and two different filler wires are used for each process. The sequence of weld passes employed for the experimentation is shown in Figure 1. The interpass time and interpass temperature are maintained between the passes ${ }^{14,15}$. After each pass, the interpass temperature is maintained below $150^{\circ} \mathrm{C}$ to avoid cracking of the weld sample ${ }^{16}$. The welded samples are free from weld defects, is verified from the X-Ray radiography NDT inspection samples are shown in Figure 2.

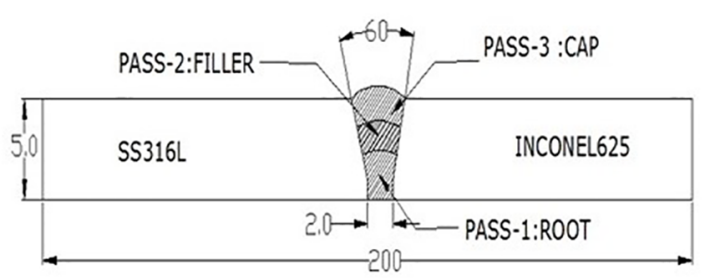

Figure 1. Schematic diagram of multipass process

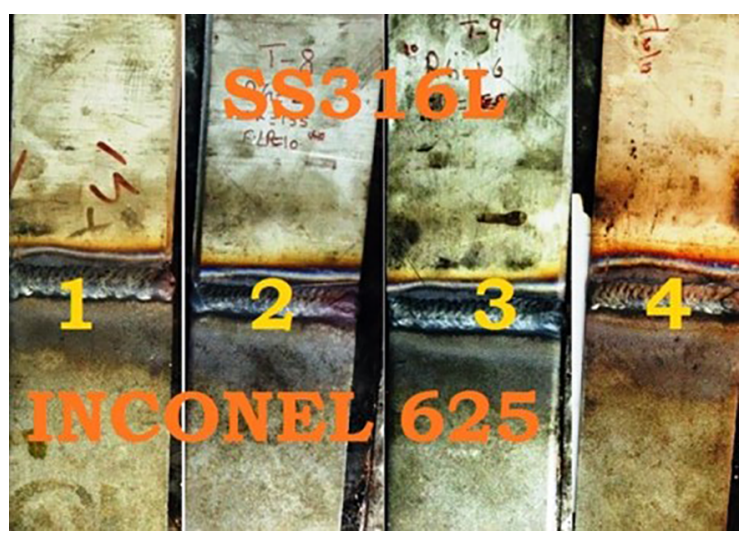

Figure 2. GTA Welded samples

\section{Residual Stress}

Residual stresses caused by thermal stresses even after external forces are removed in the material. The axial residual stress is measured in the transverse direction (weld direction) on the surface of the weldment by using the X-ray diffraction with Bragg's angle is given in Equation-1.

$$
n \lambda=2 d \sin \theta
$$

where $n=$ the order of reflection beam,

$\mathrm{d}=$ interplaner lattice spacing and

$\theta=$ Bragg angle

The material is in tension, the d-spacing increases and when the material is in compression, the d-spacing decreases are varied due to welding parameters and its cooling rate. The residual stresses are uneven in distribution either sides of the weldments due to its thermal properties (thermal expansion). The residual stress measurement was carried out using the microfocus X-ray diffraction: a Bruker D8Discover ${ }^{\mathrm{TM}}$ system is shown in Figure 3, and Figure 4 shows the goniometer with head, with Vantec ${ }^{\mathrm{TM}}$ area detector and appropriate video plus laser tracking. Measured, at the centre of the tube cross-section using standard d- $\sin ^{2} \Psi^{17,18}$. Residual stress is measured at Fusion zone of weld material; of the lateral surface on weld samples, for calculation ${ }^{19}$ of the residual stress, the following Equation-2 is used.

$$
\sigma_{\phi}=\frac{m}{d_{0}}\left(\frac{E}{1+v}\right)
$$

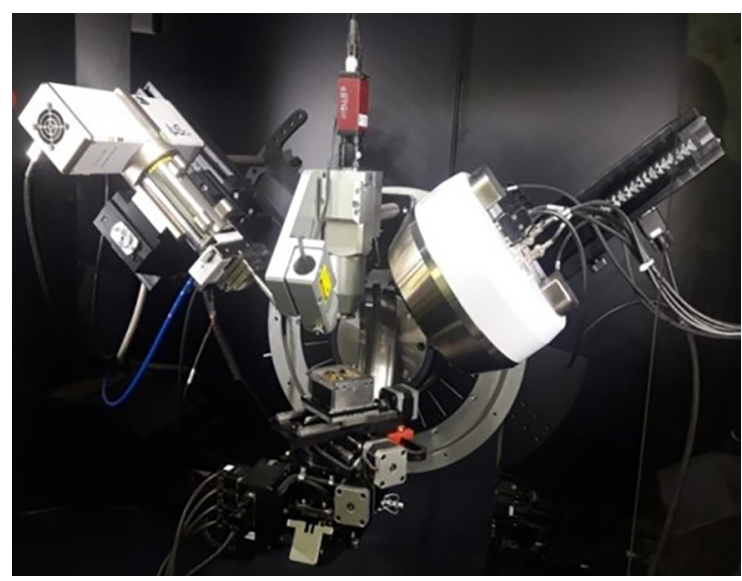

Figure 3. Bruker X-Ray Diffraction

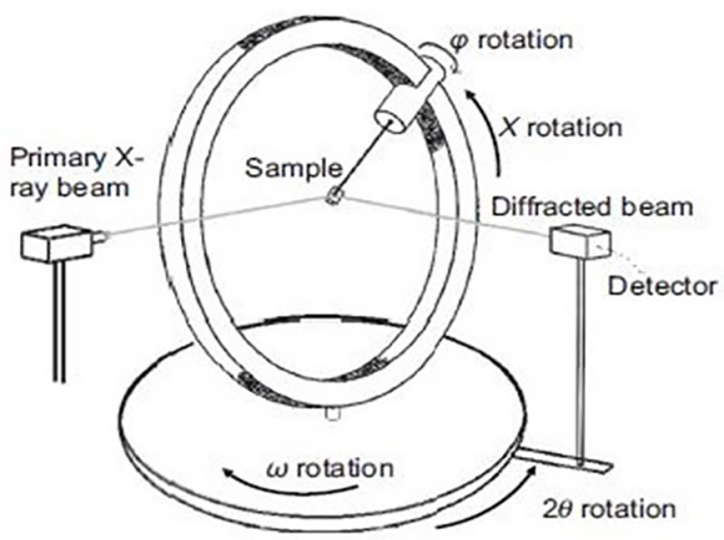

Figure 4. Schematic of goniometer head with detector

The X-Ray Diffraction waves are picked up by detectors positioned detector mounted on an arc-shaped goniometer, with a diffraction angle $(2 \theta)$, it ranges from of $20^{\circ}-90^{\circ}$. In Figure 5 the peak positions were observed for all samples. Obtaining a diffraction peak of suitable intensity is important. The peaks must be free of interference from neighbouring peaks. So that the diffraction angle $2 \theta$ can be measured experimentally and the $\mathrm{d}$-spacing is then calculated using Bragg's law. The $2 \theta$ value is 74.6 and shown in Figure 5. The strategy of stress estimations includes recording the profile of diffraction at various angle points $\psi$ with an interplanar spacing of "d". Using the resultant d spacing vs $\operatorname{Sin}^{2} \psi$ plot shown in Figure 6, the magnitude of 
surface residual stresses in the given direction is estimated $20,21,22,23$. The other two parameters are width and intensity of diffraction measuring of peaks in work surface can give the better microstructure data identified in the explored surface. Related grain size and deformation represent the diffraction peak at different $\psi$ inclination angles.

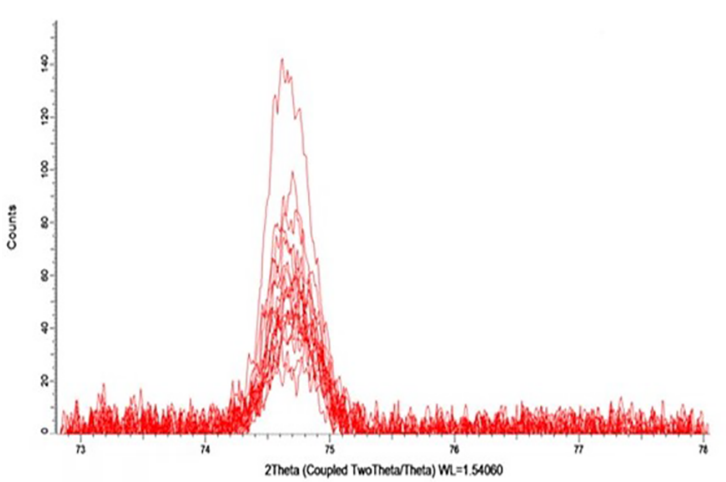

Figure 5. 2theta measurement $\theta=74.6$

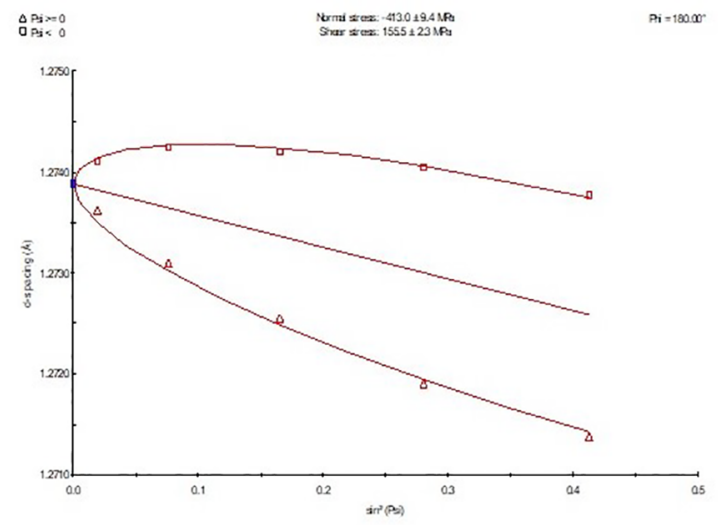

Figure 6. D spacing vs $\sin ^{2} \Psi$
Figure 6 shows the regular $d \mathrm{vs} \sin ^{2} \Psi$ for the weldment at fusion zone and for calculating the residual stress Equation-2 were used. The data of $\mathrm{d}_{0}$ is also taken from Figure 6, slope ' $\mathrm{m}$ ' is measured by drawing lines between $\mathrm{d}$ spacing and $\sin ^{2} \Psi, \mathrm{E}$ and $\mathrm{v}$ are Young's modulus and Poisson's ratio of the materials. The individual measured value of $d v \sin ^{2} \Psi$ is used for slope ' $m$ ' and this is used for calculating the residual stress using Equation-2 for all combinations. The residual stresses of various combinations are shown in Table 4.

\section{Results and Discussions}

The aspect ratio of the weldment various with the process parameters used for both CC and PC GTAW process. The welded bead geometry was measured at the lateral surface of the plates; measurement was taken place in horizontal and vertical directions of in the thickness of the weldments are shown in Table 5. The higher depth of penetration is preferable for the weldments and lower the bead width. The larger the bead width is observed in lower root opening and better depth of penetration for all the weldments.

In the design of experiments, the objective is to identify the critical parameters which will help in obtaining the desired outputs. In the welding process, we will like the output of temperature, residual stress and distortion to have minimum mean and lower the better. To obtain these outputs, we have identified parameters: voltage, current, root gap and flow rate as the parameters. These might be critical parameters or may not be, No-Way Anova estimate indicates whether these parameters critical are not. In No-Way they are two parameters mean, and variation about the mean, the sum of squares of errors gives us an indication of this

Table 4. Bead geometry characteristics of the GTA welding processes weldments

\begin{tabular}{|c|c|c|}
\hline Sample Id & Photo of sample & \\
\hline Trail-1 & & $\begin{array}{c}\text { Horizontal line-1: } 9.84 \\
\text { Horizontal line }-2: 4.29 \\
\text { Horizontal line-3: } 3.23 \\
\text { Vertical line }: 5.5 \\
\text { Bead height }: 0.88\end{array}$ \\
\hline Trail-2 & & $\begin{array}{c}\text { Horizontal line-1: } 8.99 \\
\text { Horizontal line }-2: 6.01 \\
\text { Horizontal line-3: } 7.59 \\
\text { Vertical line: } 4.97 \\
\text { Bead height : } 1.18\end{array}$ \\
\hline Trail-3 & & $\begin{array}{c}\text { Horizontal line-1: } 11.16 \\
\text { Horizontal line }-2: 6.69 \\
\text { Horizontal line-3: } 6.38 \\
\text { Vertical line: } 4.97 \\
\text { Bead height : } 1.08\end{array}$ \\
\hline Trail-4 & & $\begin{array}{c}\text { Horizontal line-1: } 9.15 \\
\text { Horizontal line }-2: 7.12 \\
\text { Horizontal line-3: } 8.49 \\
\text { Vertical line: } 5.19 \\
\text { Bead height }: 0.74\end{array}$ \\
\hline
\end{tabular}


Table 5. Residual stress of the weldments

\begin{tabular}{lccccc}
\hline S.No & Process & Root gap & Filler & Heat input & Residual stress \\
\hline & & $\mathrm{mm}$ & & $\mathrm{kJ} / \mathrm{mm}$ & $\mathrm{kJ} / \mathrm{mm}^{2}$ \\
\hline 1 & CC & 1.8 & ERNiCr-3 & 0.86 & 157 \\
2 & CC & 2.0 & ERNiCrMo-3 & 1.25 & 180 \\
3 & PC & 1.8 & ERNiCrMo-3 & 0.74 & 138 \\
4 & PC & 2.0 & ERNiCr-3 & 1.16 & 183 \\
\hline
\end{tabular}

variation. If the variation is less the selected parameters are not effective and may not effective if the variation is more, we might have included critical parameters in our experimentation. This objective of doing No-way Anova first before doing Anova.

This is the analysis of the data without any parameter being assigned, that is the reason for the word No Way. In This analysis, the response is residual stress which has a requirement of Lower the better. In No Way ANOVA, a variation of all data about reference point zero is evaluated. In No Way, two variants are seen

i Variation of mean about zero

ii Variation of the individual values about Average (called experimental errors)

Total Number of Experiments is $\mathrm{N}=4$. The data of mean and each residual value for four experiments is shown in Figure 7, has response residual stress varying about zero also the mean varying about zero. The values of Sum of Squares of mean, $\mathrm{SS}_{\mathrm{m}}$, Total Sum of Squares, $\mathrm{SS}_{\mathrm{T}}$ are shown in Table 6. From these two values, Sum of Squares of Error, $\mathrm{SS}_{\mathrm{e}}$ are calculated as $\mathrm{SS}_{\mathrm{e}}=\mathrm{SS}_{\mathrm{T}}-\mathrm{SS}_{\mathrm{m}}$. Sum of squares gives the variance.

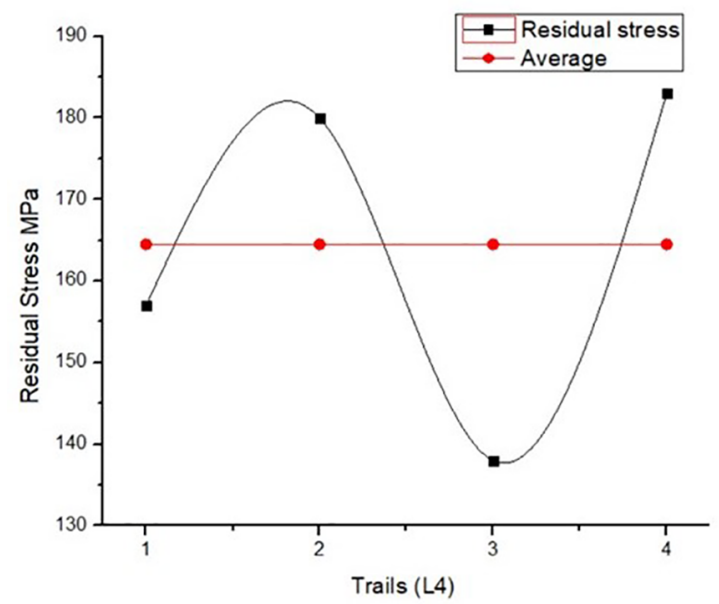

Figure 7. Variation of mean and data about zero

Akella ${ }^{24,25}$ has given a method comparison of variance hypothesis test of significance called F-test. In No-Way
Table 6. Calculation of Sum of Squares

\begin{tabular}{lc}
\hline $\mathrm{SST}=\Sigma \mathrm{Yi}^{2}$ & 109582 \\
\hline $\mathrm{Sum}, \mathrm{S}=\Sigma \mathrm{Yi}$ & 658 \\
Avg. $\mathrm{T}=\mathrm{Sum} /$ Expts. $=\mathrm{S} / \mathrm{N}$ & 164.5 \\
$\mathrm{SSm}=\mathrm{S}^{2} / \mathrm{N}=\mathrm{N}^{*}\left(\mathrm{~T}^{*} \mathrm{~T}\right)$ & 108241 \\
$\mathrm{SSe}=\mathrm{SS}$ - $\mathrm{SSm}$, Error sum of & 1341 \\
$\mathrm{Squares}$ & \\
\hline
\end{tabular}

ANOVA, the test of hypothesis is between the variance of mean and of error. Sum of square value is same as variance, the ratio of $\mathrm{SS}_{\mathrm{m}}, \mathrm{SS}_{\mathrm{e}}$ is compared with the $\mathrm{F}_{\alpha, v 1, v 2 \text {, where } \alpha}$ is the risk and $(1-\alpha)$ is the significance, $v 1$ is the degrees of freedom (DOF) of the numerator, which is of mean and $v 2$ is the dof of the denominator which is of error. If $\mathrm{F}_{0.01, v 1, v 2}$ is greater than $\mathrm{F}_{\text {calculated }}$ then the null hypothesis is rejected, and alternate hypothesis is accepted to a significance of (1- $\alpha)$.

From Table 7. $\mathrm{F}_{\text {calculated }}$ is greater than $\mathrm{F}_{0.05,1,3}$ and is also greater than $\mathrm{F}_{0.01,1,3}$ with $99 \%$ confidence we can say variance of mean and variance of error belong to different estimates. That is a variation of mean, from zero level, is a significant parameter. Experiments are going to give significant results up to $99 \%$ confidence. The No-way ANOVA, the design of experiments, selection of parameters and levels are effective in identifying the critical parameters as shown by the variation of 138 to $183 \mathrm{MPa}$ about the mean value.

In Table 8., the ANOVA summary for the parameters on effect on residual stress is calibrated. As $\mathrm{F}_{\text {caluculated }}$ is greater than $\mathrm{F}_{.01,1,5}$ filler wire selection is important to control residual stresses with $95 \%$ confidence we can say factor B, Root Gap is important. Level 1 is $1.8 \mathrm{~mm}$, and the residual stresses are $78 \mathrm{MPa}$ lower than level 2 of root gap 2.0 the residual stress is $100 \mathrm{MPa}$ as shown in Figure 8 . The welding process pulsed current process is not significant with level 2 shows better residual stress than continuous current as shown in Figure 9. The Level 1 is filler wire with Molybdenum (Mo), this is giving residual stress of $138 \mathrm{MPa}$, and Level 2 is filler wire without Molybdenum (No Mo), this is giving residual stress of $183 \mathrm{MPa}$. As the required response is lower the better, Filler wire with Mo, ERNiCrMo-3 is giving low stresses but not significant as shown in Figure 10. 
Table 7. No Way ANNOVA

\begin{tabular}{lccccccc}
\hline Source & SS & DOF & Variance & F-Table & F.1,1,3 & F..05,1,3 & F.01,1,3 \\
\hline Mean, $\mathrm{SS}_{\mathrm{m}}$ & 108241 & 1 & 108241 & 242.1498881 & 5.54 & 10.1 & 34.1 \\
Error, $\mathrm{SS}_{\mathrm{e}}$ & 1341 & 3 & 447 & & & & \\
Total, $\mathrm{SS}_{\mathrm{T}}$ & 109582 & 4 & & & & & \\
\hline
\end{tabular}

Table 8. ANOVA Summery

\begin{tabular}{|c|c|c|c|c|c|c|c|c|}
\hline Source & SS & DOF, $v$ & Variance, V & F-Table & F. $1,1,5$ & F...05,1,5 & F.01,1,5 & $\begin{array}{c}\mathrm{P}, \% \\
\text { Contribution }\end{array}$ \\
\hline A, Process & 64 & 1 & 64 & 0.52892562 & 4.06 & 6.61 & 16.8 & 4.377565 \\
\hline B, Root Gap & 1156 & 1 & 1156 & 9.553719008 & & ++ & & 79.06977 \\
\hline $\begin{array}{l}\mathrm{C}, \text { Filler } \\
\text { wire }\end{array}$ & 121 & 1 & 121 & 1 & & & & 8.276334 \\
\hline Error & 121 & 1 & 121 & & & & & 8.276334 \\
\hline $\mathrm{SS}_{\mathrm{T}}$ & 1462 & 4 & & & & & & 100 \\
\hline
\end{tabular}

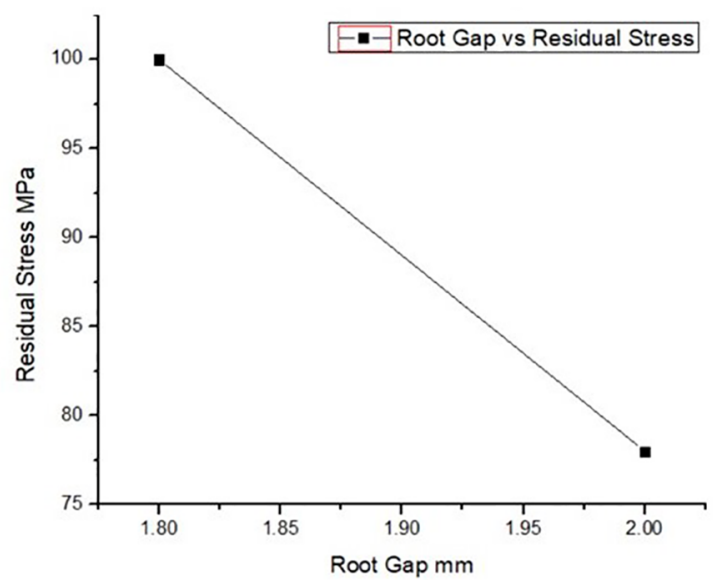

Figure 8. Effect of root gap on residual stress

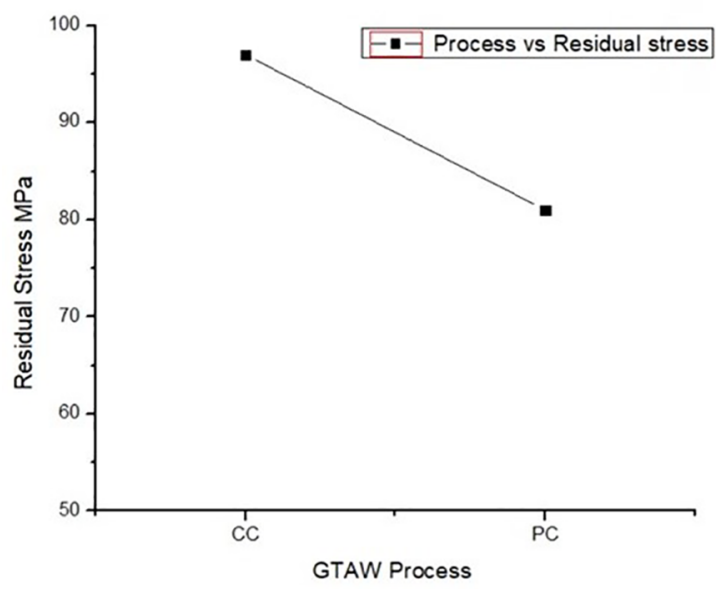

Figure 9. Effect of process on residual stress

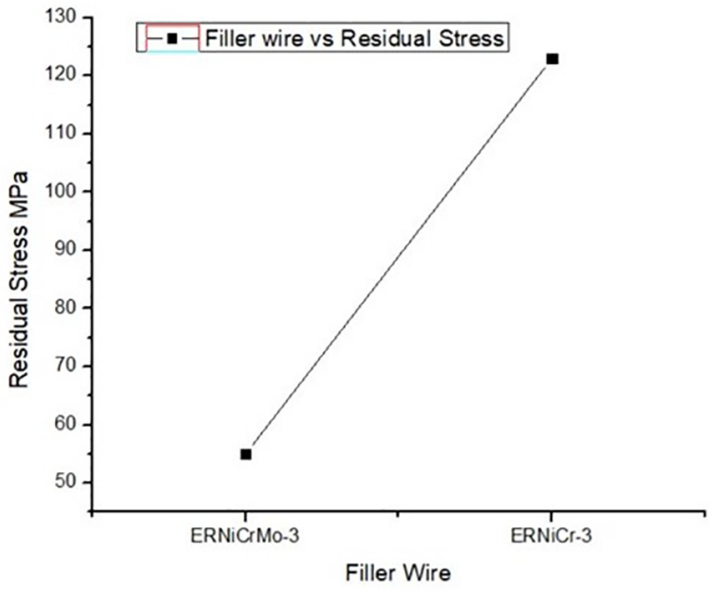

Figure 10. Effect of Filler wire on residual stress

\section{Conclusions}

The dissimilar materials; SS316L and IN625, were welded with constant current and pulsed current GTAW process with different filler wires and root gaps. The weldments are free from defects, and the same is verified using Radiography. The No-Way ANOVA by Taguchi was calculated and has shown that the experiments have a critical parameter with $99 \%$ confidence. Residual stresses were found using X-ray diffraction (XRD), and only root gap parameter was found critical with 95\% confidence; both filler wire and welding process had no significant effect on residual stress. For least residual stress the levels of welding parameters recommended are $1.8 \mathrm{~mm}$ Root gap, the pulsed current process of welding and ERNiCrMo-3 filler wire, the expected residual stress is $138 \mathrm{MPa}$ which gives a factor of safety of 1.4 for SS316L material and 1.5 for IN625. This procedure can be effectively utilized to reduce residual weld stress in the design of structures with GTAW processes. 


\section{Acknowledgement}

The authors also acknowledge support from the National Facility of Texture and OIM - A DST-IRPHA facility at IIT Bombay.

\section{References}

1. Capriccioli A, Frosi P. Multipurpose ANSYS FE procedure for welding processes simulation. Fusion Engineering and Design. 2009;84(2-6):546-553.

2. Vemanaboina H, Akella S, Buddu RK. Welding Process Simulation Model for Temperature and Residual Stress Analysis. Procedia Materials Science. 2014;6:1539-1546.

3. Akella S, Harinadh V, Krishna Y, Buddu RK. A Welding Simulation of Dissimilar Materials SS304 and Copper. Procedia Materials Science. 2014;5:2440-2449.

4. Akella S, Vemanaboina H, Buddu RK. Effect of Heat Flow Condition in Analysis of Electron Beam Welding. Sreyas International Journal of Scientists and Technocrats. 2016;1(1):1-9.

5. Murugan S, Rai SK, Kumar P, Jayakumar T, Raj B, Bose MSC. Temperature distribution and residual stresses due to multipass welding in type 304 stainless steel and low carbon steel weld pads. International Journal of Pressure Vessels and Piping. 2001;78(4):307-317.

6. Umapathi A, Swaroop S. Residual stress distribution in a laser peened Ti-2.5Cu alloy. Surface and Coatings Technology. 2016;307(Pt A):38-46.

7. Xu L, Zhang SY, Sun W, McCartney DG, Hyde TH, James J, et al. Residual stress distribution in a Ti-6Al-4V T-joint weld measured using synchrotron X-ray diffraction. The Journal of Strain Analysis for Engineering Design. 2015;50(7):445-454.

8. Vasantharaja P, Vasudevan M, Palanichamy P. Effect of welding processes on the residual stress and distortion in type 316LN stainless steel weld joints. Journal of Manufacturing Processes. 2015;19:187-193.

9. Rai S, Jayakumar T, Rao CB, Bhattacharya DK, Raj B. Residual stress measurement in ferritic steel tube welds using X-ray diffraction. Science and Technology of Welding and Joining. 1998;3(4):204-207.

10. Mohanty S, Arivarasu M, Arivazhagan N, Phani Prabhakar KV. The residual stress distribution of $\mathrm{CO}_{2}$ laser beam welded AISI 316 austenitic stainless steel and the effect of vibratory stress relief. Materials Science and Engineering: A. 2017;703:227-235.

11. Azizpour MJ, Nourouzi S. Evaluation of surface residual stresses in HVOF sprayed WC-12Co coatings by XRD and ED-hole drilling. Journal of Mechanical Science and Technology. 2013;27(9):2709-2713.
12. Kumar KG, Ramkumar KD, Arivazhagan N. Characterization of metallurgical and mechanical properties on the multi-pass welding of Inconel 625 and AISI 316L. Journal of Mechanical Science and Technology. 2015;29(3):1039-1047.

13. Javadi Y, Afzali O, Raeisi MH, Najafabadi MA. Nondestructive Evaluation of Welding Residual Stresses in Dissimilar Welded Pipes. Journal of Nondestructive Evaluation. 2013;32(2):177-187.

14. Buddu RK, Chauhan N, Raole PM. Mechanical properties and microstructural investigations of TIG welded $40 \mathrm{~mm}$ and $60 \mathrm{~mm}$ thick SS 316L samples for fusion reactor vacuum vessel applications. Fusion Engineering and Design. 2014;89(12):3149-3158.

15. Buddu RK, Chauhan NL, Raole PM. Investigations of Microstructure and Mechanical Properties of 60-mm-Thick Type 316L Stainless Steel Welded Plates by Multipass Tungsten Inert Gas Welding and Electron Beam Welding for Fusion Reactor Applications. Fusion Science and Technology. 2014;65(2):248-254.

16. Chandel R. Effect of Welding Parameters and Groove Angle on the Soundness of Root Beads Deposited by the Saw Process. Ottawa: Energy, Mines and Resources Canada, CANMET; 1985.

17. Kumar G, Balo S, Dhoble A, Singh J, Singh R, Srivastava D, et al. Through-Thickness Deformation Gradient in a Part-Pilgered Zirconium Tube: Experimental Measurements and Numerical Validation. Metallurgical and Materials Transactions A. 2017;48(6):2844-2857.

18. Kumar G, Kanjarla AK, Lodh A, Singh J, Singh R, Srivastava D, et al. Burst Ductility of Zirconium Clads: The Defining Role of Residual Stress. Metallurgical and Materials Transactions A. 2016;47(8):3882-3896.

19. Anderoglu O. Residual Stress Measurement Using X-ray Diffraction [Thesis]. College Station: Texas A \& M University; 2005.

20. Cullity BD. Elements of X-ray Diffraction. $2^{\text {nd }}$ ed. Boston: Addison-Wesley; 1978.

21. Noyan IC, Cohen JB. Residual Stress - Measurement by Diffraction and Interpretation. New York: Springer; 1987.

22. Ganesh P, Nagpure DC, Kaul R, Gupta RK, Kukreja LM. Non-destructive Micro-structural Characterization of Metallic Specimens with a Portable X-ray Diffraction based Residual Stress Analyzer. Studies in Engineering and Technology. 2015;2(1):22-32.

23. Kim CS, Hong KS, Kim MK. Nonlinear robust control of a hydraulic elevator: experiment-based modeling and twostage Lyapunov redesign. Control Engineering Practice. 2005;13(6):789-803.

24. Akella S, Kumar BR, Krishnaiah Y. Optimisation of welding process parameters for distortion control with Taguchi approach. International Journal of Precision Technology. 2013;3(2):206-219.

25. Ross PJ. Taguchi Techniques for Quality Engineering. $2^{\text {nd }} e d$. New York: McGraw-Hill; 1996. 


\section{Erratum}

In the article "Effect of Residual Stresses of GTA Welding for Dissimilar Materials", DOI number: http://dx.doi. org/10.1590/1980-5373-mr-2017-1053, published in Materials Research, 21(4):1,

Where was written:

Harinadh Vemanaboina ${ }^{a^{*}}$

Gundabattini Edison ${ }^{\mathrm{a}}$

Suresh Akella ${ }^{\mathrm{b}}$

Ramesh Kumar Buddu ${ }^{\mathrm{c}}$

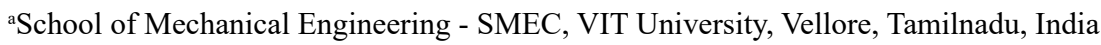

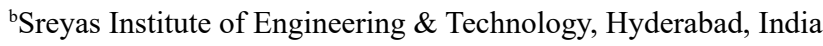

'Institute for Plasma Research, Gandhinagar, Gujarat, India

Should be read:

Harinadh Vemanaboina ${ }^{*}$ (D)

Gundabattini Edison ${ }^{\mathrm{a}}$

Suresh Akella ${ }^{\mathrm{b}}$

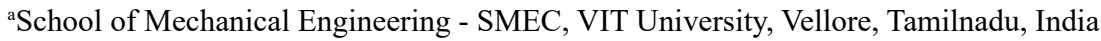
${ }^{\mathrm{b}}$ Sreyas Institute of Engineering \& Technology, Hyderabad, India 